\title{
A dominant negative PPAR $\gamma$ mutant shows altered cofactor recruitment and inhibits adipogenesis in 3T3-L1 cells
}

\author{
Y. Park, B. D. Freedman, E. J. Lee, S. Park, J. L. Jameson \\ Division of Endocrinology, Metabolism and Molecular Medicine, Northwestern University Medical School, Chicago
}

\begin{abstract}
Aims/hypothesis. PPAR $\gamma$, a member of the nuclear hormone receptor family of transcription factors, plays a key role in adipocyte differentiation and insulin sensitivity. The aim of this study was to identify a potential dominant negative murine PPAR $\gamma$ mutant and to characterize the in vitro functional properties of this mutant. Methods. In vitro transient transfections and mammalian two-hybrid assays in TSA201 cells were used to characterize the transcriptional activity of the L466A mutant and to study the molecular interaction of transcriptional cofactors with the L466A mutant in an attempt to elucidate the mechanism of its dominant negative activity. Adenoviral constructs expressing PPAR $\gamma$ wild-type (AdWT) or the L466A mutant (AdL466A) were infected into the murine 3T3-L1 cell line to study the mutant's effect on adipogenesis.

Results. The L466A mutant alone is transcriptionally defective. However, it retains DNA binding and inhib-
\end{abstract}

its the ligand-dependent and -independent activity of the wild-type receptor, consistent with dominant negative properties. In mammalian two-hybrid studies, the L466A mutant does not bind nuclear receptor coactivators. However, it more avidly recruits corepressors due to enhanced binding to the corepressor ID1 domain, leading to pronounced transcriptional repression. The AdL466A mutant inhibits adipogenesis induced by either a differentiation cocktail or by thiazolidinedione ligand. AdL466A infection also blocked the upregulation of the adipocyte marker genes aP2 and adipsin.

Conclusion. We conclude that the L466A PPAR $\gamma$ mutant possesses potent dominant negative activity based on preferential corepressor recruitment and it inhibits adipogenesis and the expression of adipocyte-specific genes. [Diabetologia (2003) 46:365-377]

Keywords Dominant negative, PPAR $\gamma$, thiazolidinedione, adipogenesis, adenovirus, protein-protein interaction, 3T3-L1 cells.
Received: 9 September 2002 / Revised: 12 November 2002

Published online: 7 March 2003

C) Springer-Verlag 2003

Corresponding author: J. L. Jameson MD PhD, Department of Medicine, Northwestern Memorial Hospital, Galter 3-150, 251 E. Huron St., Chicago, IL 60611, USA

E-mail: ljameson@northwestern.edu

Abbreviations: AD, activation domain; AdGal, adenoviral directed $\beta$-galactosidase; $\mathrm{AF}-2$, activation function domain-2; $\mathrm{aP} 2$, adipose protein2/fatty acid binding protein; BRL, BRL49653; $\mathrm{C} / \mathrm{EBP}$, CCAAT enhancer binding protein; CMV, cytomegalovirus; DBD, DNA binding domain; ID, interaction domain; LBD, ligand binding domain; MDI, differentiation cocktail; NCoR, nuclear corepressor; PBP, PPAR binding protein; Pfu, plaque forming unit; PPAR, peroxisome proliferator activated receptor; PPRE, PPAR response element; RT, reverse transcription; RXR, retinoid X receptor; SRC-1, steroid receptor coactivator-1; TZD, thiazolidinedione; UAS, upstream activating sequence.
The first two authors contributed equally to this work. Peroxisome proliferator-activated receptor gamma (PPAR $\gamma$ ), a member of the nuclear hormone receptor superfamily of ligand-activated transcription factors, plays an important role in various biological processes including adipocyte differentiation and glucose homeostasis $[1,2]$. The binding of PPAR $\gamma$ to PPARresponse elements (PPREs) is critical for the activation of many adipocyte specific genes [3]. PPAR $\gamma$ shares a modular structure with other members of the superfamily and has the typical amino-terminal A/B domain, DNA binding domain (DBD) containing two zinc fingers, and ligand binding domain (LBD) that includes $\alpha$-helix 12 at the C-terminus. PPAR $\gamma$ heterodimerizes with the retinoid $\mathrm{X}$ receptor (RXR) [4], and 
this heterodimer binds to PPREs in target genes [5] and activates transcription upon the addition of ligand. Activation function domain 2 (AF-2) in helix 12 at the $\mathrm{C}$-terminal region is highly conserved among nuclear receptors including PPAR $\gamma$ [6]. Helix 12 contributes to the conformational change necessary for cofactor recruitment, a requirement for ligand-dependent activation [7, 8] or ligand-independent repression [9] of transcription. PPAR $\gamma$ has been reported to recruit cofactors to activate or repress transcription, including SMRT [10, 11], CBP/p300 [12, 13], SRC-1 [8], PBP/TRAP220 [14, 15], and PGC-1 [16].

In addition to PPAR $\gamma$, adipocyte differentiation is regulated by several other transcription factors including CCAAT enhancer binding proteins $(\mathrm{C} / \mathrm{EBP})$ and adipocyte differentiation and determination factor 1/ sterol regulatory element binding protein 1 (ADD-1/ SREBP-1) [3]. Among these factors, PPAR $\gamma$ has emerged as a key regulator of adipogenesis. PPAR $\gamma$ null mice were generated to examine the role of PPAR $\gamma$ in vivo. However, the homozygous null mice could not be studied in depth due to placental dysfunction and embryonic lethality at E10-10.5 [17, 18]. PPAR $\gamma$ null ES cells did not undergo adipocyte differentiation after hormone treatment (dexamethasone and methylisobutylxanthine) in vitro [19]. In contrast, PPAR $\gamma$ was able to promote adipogenesis in $\mathrm{C} / \mathrm{EBP} \alpha-$ deficient cells, whereas $\mathrm{C} / \mathrm{EBP} \alpha$ did not promote adipogenesis in PPAR $\gamma$-deficient cells [20]. These experiments support a key role for PPAR $\gamma$ as a regulator of adipogenesis. Additional evidence indicates that cofactor availability to PPAR $\gamma$ is also important in the regulation of adipogenesis. For example, ribozymemediated depletion of CREB-binding protein (CBP) inhibits adipocyte differentiation [13], and ectopic expression of PPAR $\gamma$ in TRAP220 null fibroblasts does not induce adipogenesis [15].

PPAR $\gamma$ also plays an important role in insulin sensitivity. The thiazolidinediones (TZDs), potent insulin sensitizing agents that lower blood glucose values in patients with Type 2 diabetes [21], are high affinity PPAR $\gamma$ ligands $[22,23,24]$. The activation of PPAR $\gamma$ by TZDs improves insulin sensitivity, but results in body weight gain, possibly due to augmented adipogenesis. The precise mechanism by which PPAR $\gamma$ improves insulin sensitivity remains unclear but could involve decreased free fatty acids secondary to enhanced lipid storage [25]. Two heterozygous PPAR $\gamma$ mutations (P467L and V290M) have been identified in the LBD in human subjects with severe insulin resistance and diabetes [26]. These mutations were suggested to exert dominant negative activity, thereby impairing the function of the normal PPAR $\gamma$ allele. Another study [27] created a potent artificial human PPAR $\gamma$ dominant negative mutant by altering two residues (L468Q/E471A) in the coactivator contact surface of the carboxy terminal AF-2. This double mutant inhibited adipogenesis when introduced into 3T3-
L1 cells [28]. As a prelude to creating an in vivo knock-in PPAR $\gamma$ mutant, we carried out detailed in vitro studies on the murine PPAR $\gamma$ L466A mutant, which corresponds to human L468. In addition to the previous studies of human PPAR $\gamma$, the selection of the L466A mutant in mouse PPAR $\gamma$ was based on alignment with previously described dominant negative mutants (TR $\beta$ L454) in the human thyroid hormone receptor $\beta$ (TR $\beta)$. Mutations in this homologous Leu residue cause a particularly severe form of resistance to thyroid hormone and in vitro studies document impaired binding to coactivators [29]. X-ray crystallographic data confirm that the Leu at 468 in human PPAR $\gamma$ (Leu 466 in mouse PPAR $\gamma$ ) provides essential hydrophobic interactions with the LXXLL motif of steroid receptor coactivator-1 (SRC-1) [8]. We find that the murine L466A mutant shows strong dominant negative activity and inhibits both ligand- and hormone-induced adipogenesis.

\section{Materials and methods}

Plasmid construction. The mouse PPAR $\gamma 1$ cDNA (J. Reddy, Northwestern) was subcloned into pCMX expression vectors [30] using KpnI and SmaI restriction sites. A series of deletion mutants was generated by polymerase chain reaction (PCR) from the C-terminal region of PPAR $\gamma$. Seven mutants were constructed by deleting the last five amino acids of the 474 amino acid full length PPAR $\gamma$ followed by groups of three consecutive amino acids from the carboxy-terminus codon to generate 469X, 466X, 463X, 460X, 457x, 454x, and 451x. A single point mutant, L466A, and a double point mutant E127G/G128S (DBDm), were generated by PCR site-directed mutagenesis. All constructs were confirmed by DNA sequencing (Perkin-Elmer Corp, Norwalk, Conn., USA).

The LBD, amino acid 162 to stop codon, of wild-type PPAR $\gamma 1$ or the L466A mutant were introduced into a VP16 backbone vector (AASV, [31]) by inserting the LBD downstream of cDNA encoding the VP16 transactivation domain (AD) using 3-piece ligation. The fragment of PPAR $\gamma$ from amino acid 162 to amino acid 198 was amplified from pCMX PPAR $\gamma 1$ and a new in frame $5^{\prime}$ EcoRI site was created. This piece was digested with EcoRI and EcoRV and ligated with a PPAR $\gamma$ fragment (aa198 to stop codon) also digested with EcoRV and HindIII, and the VP16 vector digested with EcoRI and HindIII. The resulting plasmids were named VP16 WT and VP16 L466A. The same fragments were subcloned into pSG424 [32] to generate the Gal4WT-LBD and Gal4L466ALBD. The Gal4 DNA binding domain in pSG424 was used as a control. Construction of VP16-SRC-1 was described previously [33]. Interaction domains of PPAR binding protein (PBP) (J. Reddy, Northwestern), amino acids 533 to 773, were amplified by PCR and inserted into the VP16 vector. An Ile to Thr mutation was created in the hydrophobic core region of interaction domain 1 (ID1) of human silencing mediator for retinoic and thyroid hormone receptors (hSMRT) (M.G. Rosenfeld, UCSD) and mouse nuclear corepressor (mNCoR) (R. Evans, Salk Institute), amino acids 2346 and 2281, respectively, using overlapping PCR site-directed mutagenesis. ID1 and the mutated interaction domain 1 (ID1M) of hSMRT and mNCoR from amino acids 2267 to 2352 and 2204 to 2370, respectively, were amplified from $\mathrm{pCMX/hSMRT}$ and $\mathrm{pCMX/}$ 
$\mathrm{mNCoR}$ and subcloned into pSG424 (downstream of Gal4 DNA binding domain) using EcoRI and NheI/XbaI digests. Interaction domain 2 (ID2) of hSMRT and mNCoR from amino acids 2098 to 2266 and 2035 to 2203 , respectively, were amplified and subcloned into the Gal4 vector. In addition, both interaction domains (ID1+ID2) were combined using PCR amplification and subcloned into the Gal4 vector. The resulting plasmids were named Gal4 ID1, Gal4 ID1 M, Gal4 ID2, and Gal4 ID1+2 for both hSMRT and mNCoR.

Two copies of the acyl-CoA oxidase (ACO) PPRE (5'-AGC TTA GGG GAC CAG GAC AAA GGT CAC GTT CGG GAG TCG ACA GGG GAC CAG GAC AAA GGT CAC GTT CGG GAC-3') were subcloned into a reporter with the minimal thymidine kinase promoter (TK109) and luciferase gene [34] to generate 2XPPRE-TK-Luc as a reporter plasmid. The UASE1b-TATA-Luc reporter contains five copies of the upstream activating sequence (UAS) upstream of E1b-TATA in the pA3Luc vector [35].

Generation of transfer plasmids and recombinant adenoviral vectors. A cassette containing either the wild-type or mutant mouse PPAR $\gamma 1$ cDNAs driven by the cytomegalovirus (CMV) promoter/enhancer with a simian virus (SV) 40 polyadenylation $(\mathrm{p}(\mathrm{A}))$ sequence was subcloned into an adenoviral transfer plasmid based on pcDNA3 (Invitrogen, Carlsbad, Calif, USA) [36]. The resulting plasmids were used to generate recombinant adenoviruses [36]. Recombinant adenoviruses carrying wild-type PPAR $\gamma$, L466APPAR $\gamma$ and DBDmPPAR $\gamma$ were designated AdWT, AdL466A, and AdDBDm, respectively. Individual clones of the recombinant adenoviral vectors were purified and titrated by plaque assays. The sequences of the expression cassettes in the adenoviral vectors were confirmed by automated DNA sequencing. AdGal [37], which contains $\beta$ galactosidase driven by CMV promoter, was used to evaluate the efficiency of gene transduction in the cell culture system.

Cell Culture, transient tranfections, and mammalian twohybrid studies. The human embryonic kidney 293 TSA201 cells (TSA201) were maintained in Dulbecco's Modified Eagle's Medium (DMEM) with high glucose and $10 \%$ foetal bovine serum (FBS). Cells $\left(2 \times 10^{5}\right.$ cells/well $)$ were plated into 12 -well plates $24 \mathrm{~h}$ before transfection. Transfection was carried out by the calcium phosphate precipitation method [34]. Transient cotransfections were carried out with $500 \mathrm{ng}$ per well of a reporter plasmid (2XPPRE-TK-Luc) and $10 \mathrm{ng}$ per well of wild-type or mutant PPAR $\gamma$ constructs. To study dominant negative activity, an increasing amount, from $10 \mathrm{ng}$ to $100 \mathrm{ng}$, of the mutant DNA (L466A or DBDm) was added with $10 \mathrm{ng}$ per well of wild type PPAR $\gamma$ (WT). Increasing pCMX empty vector was added to each well to compensate for increased DNA concentration.

For mammalian two-hybrid studies, cells were cotransfected with an E1B-UAS-Luc reporter (50 ng/well) [38], Gal4 constructs (5-0 ng/well), and VP16 constructs (50 ng/well). Eighteen hours post-transfection, the media was aspirated and replaced with media containing $1 \mu \mathrm{mol} / \mathrm{l}$ of the BRL49653 ligand (Glaxo Smith-Kline, London) or an equivalent amount of DMSO (no ligand). Twenty-four hours after the addition of ligand, cells were lysed and luciferase assays were done using a luminometer [34]. The mean and standard errors of triplicate samples are shown for representative experiments. All transfection experiments were repeated three or four times with similar results.

Electrophoretic Mobility Shift Assays (EMSA). In vitro translation of WT, L466A, DBDm, and RXR $\alpha$ was performed using the $\mathrm{T}_{\mathrm{N}} \mathrm{T}$ reticulocyte lysate system (Promega, Madison, Wis.,
USA). Synthetic oligonucleotides corresponding to the consensus PPAR response elements were created as follows: $5^{\prime}-\mathrm{AG}$ GGGACCAGGACAAAGGTCACGTTCGGGA-3' and 5'-TCCCGAACGTGACCTTTGTCCTGGTC-3'. The probe was annealed at $95^{\circ} \mathrm{C}$ for $5 \mathrm{~min}$, cooled down to room temperature stepwise by one degree per min and labelled with [32P]dCTP by Klenow polymerase, EMSA was then carried out [34]. Briefly, each lysate $(3 \mu \mathrm{l})$ of either wild-type or mutant PPAR $\gamma$ and RXR $\alpha$ were incubated with 20 fmole of [ $\left.{ }^{32} \mathrm{P}\right]$-labelled oligonucleotides with or without BRL49653 (1 $\mu \mathrm{M})$. The DNAprotein complexes were resolved on $4 \%$ native polyacrylamide gels in $0.5 \times$ Tris-borate-EDTA (TBE) buffer.

Adenoviral infection of murine 3T3-L1 cells and adipocyte differentiation. 3T3-L1 cells (American Type Culture Collection, Manassas, Va., USA) were cultured in DMEM supplemented with $10 \%$ FBS. Transduction efficiency of adenoviral vectors in 3T3-L1 cells was tested using AdGal. $\beta$-galactosidase expression was detected in 95 to $100 \%$ of cells after $48 \mathrm{~h}$ of infection with AdGal at 1000 plaque-forming units (Pfu) per cell. Therefore, subsequent experiments were done using 1000 $\mathrm{Pfu}$ per cell of recombinant adenoviral vectors. Cells were plated in six well plates at a density of $1.5 \times 10^{5}$ cells per well and infected with adenoviral vectors $24 \mathrm{~h}$ later. Fresh media was added $24 \mathrm{~h}$ post-infection and incubated for $72 \mathrm{~h}$ to achieve and maintain confluence prior to induction of differentiation. For the induction of differentiation, cells were treated with $1 \mu \mathrm{mol} / 1$ BRL49653 and/or differentiation cocktail (MDI), $250 \mu \mathrm{mol} / \mathrm{l}$ methylisobutylxanthine, $1 \mu \mathrm{mol} / \mathrm{l}$ dexamethasone, $1 \mu \mathrm{g}$ per $\mathrm{ml}$ insulin for 2 days [39]. Media was replaced with fresh media containing $1 \mu \mathrm{mol} / 1$ BRL49653 every 2 days. After 8 days of differentiation, adipogenesis and lipid accumulation were examined by staining with Oil Red-O [40] and the expression of adipocyte specific RNA markers. For Oil Red-O staining, cells were washed gently with phosphate-buffered saline (PBS) and stained with $60 \%$ filtered Oil red-O solution stock solution ( 0.5 gram in $100 \mathrm{ml}$ isopropyl alcohol) for $20 \mathrm{~min}$. After washing cells with PBS three times, cells were kept in $75 \%$ glycerol solution and photomicrographs were taken using an inverted microscope (Leitz Wetzlar, Germany). The results are representative of three independent experiments.

Triglyceride measurements. At the end of the adipogenesis assay, $200 \mu \mathrm{l}$ of cell lysis buffer was added to each well. Triglyceride measurements were carried out using $3 \mu \mathrm{l}$ of the lysis supernatant and $150 \mu \mathrm{l}$ of Sigma Diagnostics Infinity Triglyceride Reagent (cat.\# 343-25P). Absorbance was measured at $520 \mathrm{~nm}$ in a microplate reader (Emax; Molecular Devices, Sunnyvale, Calif., USA) following a 5 min incubation at room temperature. The cellular triglyceride concentration was then calculated based on a standard curve of known glycerol dilutions.

Semi-quantitative reverse transcription $(R T)$ - $32 P$ polymerase chain reaction $(P C R)$. Total RNA was isolated from the 3T3L1 cells on the $8^{\text {th }}$ day after initiation of differentiation using Trizol solution (InVitrogen, Carlsbad, Calif., USA) and semiquantitative RT-PCR was done [41]. Expression of aP2 (fatty acid binding protein), adipsin, and cyclophilin mRNA was measured using the following primers:

aP2 antisene; $5^{\prime}$-cacattccaccaccagctt- $3^{\prime}$

aP2 sense; $5^{\prime}$-tcaccatccggtcagagagta- $3^{\prime}$

adipsin antisense; $5^{\prime}$-gatgtttcgatccacatccg- $3^{\prime}$

adipsin sense; $5^{\prime}$-cagagtgtcaatcatgaaccgg- $3^{\prime}$

cyclophilin antisense; $5^{\prime}$-ggtttctccacttcgatcttgc- $3^{\prime}$

cyclophilin sense; $5^{\prime}$-acgagtcgtctttggactctttg- $3^{\prime}$ 
A

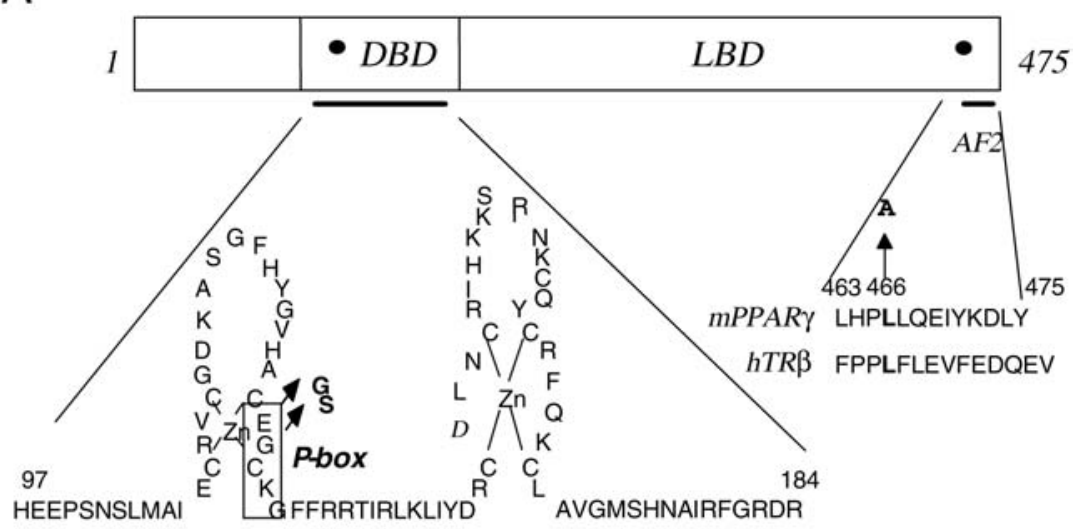

Zinc finger I Zinc finger II

B

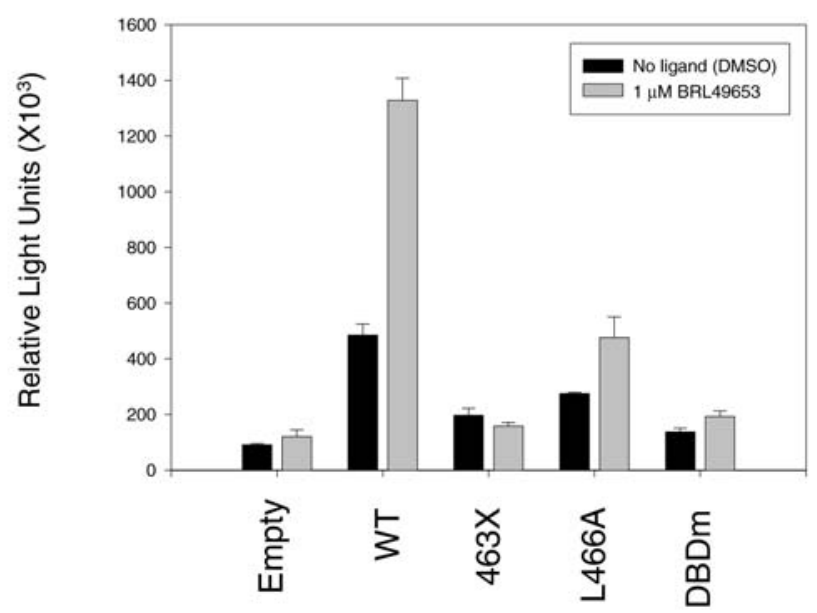

Fig. 1A, B. Transcriptional activity of PPAR $\gamma$ mutants. (A) Schematic illustration of the modular domains of PPAR $\gamma$ and location of the mutations ( ). The DBDm was created by mutation of two amino acids in the first zinc finger of the DBD, E and $\mathrm{G}$ into $\mathrm{G}$ and $\mathrm{S}$, respectively. The $463 \mathrm{x}$ mutant was created by truncation of the C-terminal of PPAR $\gamma$ up to position 463 . Helix 12 of the LBD of mPPAR $\gamma$ was aligned with that of hTR $\beta$. The leucine residue at 466 was mutated to alanine based on the naturally occurring L454 V mutation of TR $\beta$. (B) Three different PPAR $\gamma$ mutants exhibit impaired transcriptional activity relative to wild-type PPAR $\gamma$. TSA cells were cotransfected with $10 \mathrm{ng} /$ well of the indicated PPAR $\gamma$ expression vectors (pCMX, WT, 463x, L466A, DBDm) and $500 \mathrm{ng} / \mathrm{well}$ of reporter plasmid (2X-PPRE-TK-Luc) with or without $1 \mu \mathrm{mol} / 1$ ligand (BRL49653). Cells were harvested $48 \mathrm{~h}$ after ligand treatment and assayed for luciferase activity

PCR was carried out at $94^{\circ} \mathrm{C}$ for $1 \mathrm{~min}, 55^{\circ} \mathrm{C}$ for $1 \mathrm{~min}, 72^{\circ} \mathrm{C}$ for $1 \mathrm{~min}$, for 19 cycles for aP2, and 24 cycles for adipsin and cyclophilin. For semiquantitative PCR, [ $\left.{ }^{32} \mathrm{P}\right] \mathrm{dCTP}$ was added into the reaction and PCR products were separated on $6 \%$ nondenaturing polyacrylamide gels, visualized by autoradiography, and quantitation was carried out using the Molecular Analyst/PC image analysis software for the Bio Rad model GS-670 densitometer.

Western blot analysis. Whole cell extracts were prepared from TSA, or 3T3-L1 cells after completion of adipogenesis on day
8 [42]. The extracts were separated by $12 \%$ SDS-polyacrylamide gel electrophoresis, and transferred onto nitrocellulose membranes (Amersham Pharmacia Biotech, Piscataway, N.J.). Immunodetection was carried out using a rabbit PPAR $\gamma$ polyclonal antibody (Santa Cruz Biotechnology, Santa Cruz, Calif., USA) and mouse anti-rabbit, horseradish peroxidase-conjugated IgG (Cell Signalling, Beverly, Mass., USA). Proteins were visualized with an ECL+Plus detection kit (Amersham Pharmacia Biotechnology) according to the manufacturer's instructions.

\section{Results}

Delineation of the carboxy terminal functional domain of PPAR . Nuclear receptors vary widely in the number of carboxy terminal amino acids that can be deleted before there is loss of ligand binding or transcriptional activity from the AF-2. In some cases, such as for thyroid hormone receptor $\beta$ (TR $\beta$ ), deletion of as few as nine amino acids causes loss of function but acquisition of potent dominant negative activity. To characterize the transactivation activity of the carboxy terminus of murine PPAR $\gamma$, a series of deletion mutants (469X, 466X, 463X, 460X, 457x, 454x, 451x) and two point mutants (L466A, DBDm) were created. 
These point mutations were created based on mutations in other members of the nuclear receptor family. The Leu residue at amino acid 466 of PPAR $\gamma$ was changed to alanine based on the naturally occurring mutation in Leu residue at 454 of TR $\beta$ (Fig. 1A). A double point mutant (DBDm) was created by mutation of the P-box of the DBD after alignment of PPAR $\gamma$ with a mouse estrogen receptor alpha $(E R \alpha)$ mutant that possesses deficient DNA binding ability. To construct the DBDm, Glu at position 127 and Gly at position 128 of PPAR $\gamma$ were changed to Gly and Ser, respectively (Fig. 1A).

Transient transfections in TSA201 cells were used to characterize the transcriptional activity of the mutants described above compared to that of wild-type PPAR $\gamma$ (WT). Based on Western blot analysis, PPAR $\gamma$ was not detected in whole cells extracts from TSA201 cells. However, PPAR $\gamma$ was detected by western blot analysis after transfection of the pCMX-PPAR $\gamma$ expression vector. The mutants described above showed impaired transcriptional activity when compared to that of WT in the context of a luciferase reporter gene (Fig. 1B). The thiazolidinedione PPAR $\gamma$ ligand, rosiglitazone (BRL49653, $1 \mu \mathrm{mol} / \mathrm{l}$ ), induced a 3-5 fold increase in luciferase activity in cells expressing WT PPAR $\gamma$. The transactivation properties of this group of C-terminus deletion mutants were similar. The impaired transcriptional activity of 463x (C-terminus deleted from 474 to 463 ) is representative of the group, and confirms the requirement of the C-terminus for transactivation (Fig. 1B). The basal transcriptional activities of all mutants (L466A, DBDm, and 463X) were less than that of WT without BRL49653 (BRL). The addition of BRL marginally increased the transcriptional activity of the L466A mutant, but this activity was less than that of WT in the absence of ligand. The DBDm mutant was unable to activate transcription of the luciferase reporter even after the addition of ligand.

To study the DNA binding abilities of these mutants, electrophorectic mobility shift assays were carried out. In vitro translated PPAR $\gamma$ and $\operatorname{RXR} \alpha$ were incubated with a ${ }^{32} \mathrm{P}$-labelled oligonucleotide probe containing a consensus PPRE. RXR $\alpha$ was included in all reactions due to the requirement for PPAR $\gamma$ heterodimerization with RXR $\alpha$ for DNA binding. Both PPAR $\gamma$ WT and the L466A mutant were able to bind to the PPRE with or without ligand (Fig. 2). The DBDm mutant had no detectable DNA binding activity relative to PPAR $\gamma$ WT (Fig. 2). This result indicates that the reduction of transcription shown by the L466A mutant was not due to decreased DNA binding ability. In contrast to the L466A mutant, the loss of transcriptional activity shown by the DBDm mutant is likely due to the loss of DNA binding ability.

Next, we confirmed that the reduced transactivation function of L466A is dependent upon its LBD mutation. Transient transfections were done using a

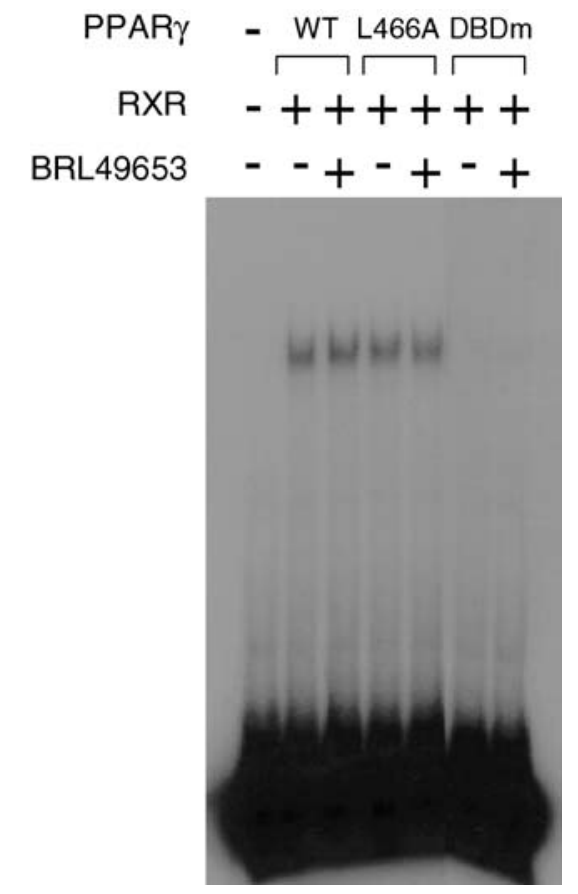

Fig. 2. DNA-binding of PPAR $\gamma$ mutants. The L466A mutant has equivalent DNA binding ability to wild-type PPAR $\gamma$, whereas the DBDm mutant no longer binds DNA. An electrophoretic mobility shift assay was carried out using an ACO PPRE probe and in vitro translated WT or mutant PPAR $\gamma$ proteins with or without ligand (BRL49653)

Gal4DBD expression vector (Gal4) containing the LBD of PPAR $\gamma$ in the context of a UAS-E1bTATALuc reporter gene (Fig. 3A). This luciferase reporter contains five copies of the UAS Gal4 response element upstream of E1b-TATA-luciferase (UAS-E1bTATA-Luc). Transfection of Gal4WT-LBD led to a 20 -fold increase in transactivation of the reporter after the addition of $1 \mu \mathrm{mol} / \mathrm{l} \mathrm{BRL}$ (Fig. 3B). Gal4L466ALBD exhibited basal suppression of the reporter without ligand, and transcriptional activity was increased only two-fold by the addition of $1 \mu \mathrm{mol} / \mathrm{l} \mathrm{BRL}$.

The L466A mutant exhibits strong dominant negative activity. The lack of transcriptional activity of the L466A mutant indicates that this mutant could possess dominant negative activity. The potential dominant negative effect of the L466A mutant was examined by cotransfection of PPAR $\gamma$ WT with equal or increasing amounts of the mutant in the context of the 2XPPRE luciferase reporter. With ligand (BRL $1 \mu \mathrm{mol} / \mathrm{l}$ ), cotransfection of an equal amount of L466A reduced the transcriptional activity of PPAR $\gamma$ by approximately $50 \%$ (Fig. 4A). Higher concentrations of the L466A mutant suppressed WT transcriptional activity comparable to that of pCMX empty vector control. Titration of WT transcriptional activity by cotransfection of the DBDm mutant required a five-fold excess of DBDm to reduce the transcriptional activity of PPAR $\gamma$ by $50 \%$ (Fig. 4B). Increasing the concentration of the 
A

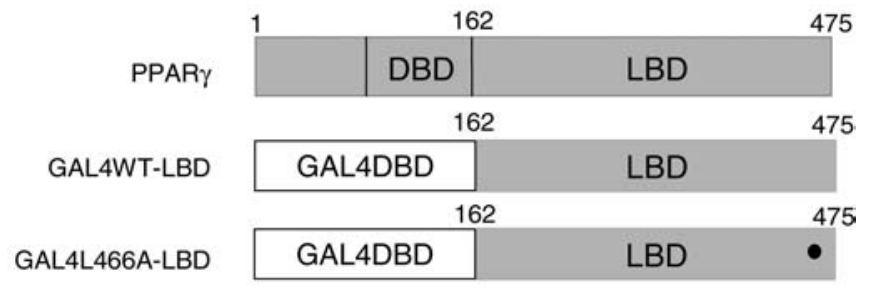

B

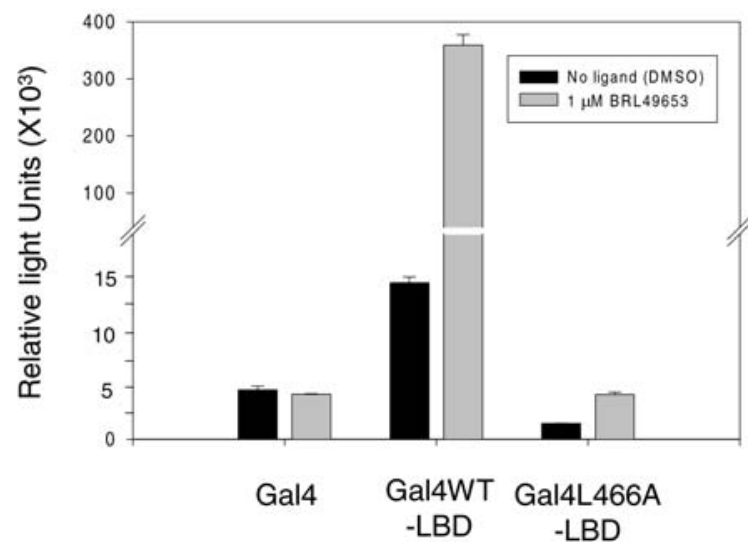

Fig. 3A, B. Reduced transcriptional activity of the L466A mutant in a mammalian one-hybrid system. (A) Schematic illustration of Gal4-PPAR $\gamma$ WT or L466A. The LBD domain of either WT or the L466A mutant $(\bigcirc)$ from amino acids 162 to 475 was subcloned downstream of the Gal4 DNA binding domain (Gal4DBD) of the pSG424 vector. (B) The LBD of the L466A mutant shows basal suppression and reduced transactivation when compared to the LBD of WT. TSA cells were cotransfected with $50 \mathrm{ng} /$ well of Gal4 constructs and $500 \mathrm{ng} /$ well of UAS-E1b-TATA-Luc reporter. Eighteen hours post-transfection, $1 \mu \mathrm{mol} / \mathrm{l}$ of BRL49653 or DMSO (control) was added with fresh media. Cells were harvested $24 \mathrm{~h}$ after ligand treatment and assayed for luciferase activity

DBDm mutant, up to $100 \mathrm{ng} / \mathrm{well}$, failed to reduce the transcriptional activity to that of the pCMX empty vector. The L466A mutant therefore exerts a strong dominant negative effect, whereas a mutant lacking DNA binding ability is unable to reduce the transcriptional activity of wild-type PPAR $\gamma$ to the same degree.

The L466A mutant shows altered cofactor recruitment and release. A mammalian two-hybrid assay was used to study the molecular interaction of transcriptional cofactors with the L466A mutant in an attempt to elucidate the mechanism of its dominant negative activity. The DBDm mutant was not included in these studies because its impaired transcriptional activity is likely due to its inability to bind and thus transactivate DNA. The mammalian two-hybrid studies consisted of a series of transient transfections with the VP16 activation domain (VP16AD) and the GAL4 DNA binding domain (Gal4DBD) in the context of the UAS reporter gene (Figs. 5A, 6A). The Leu residue mutated
A

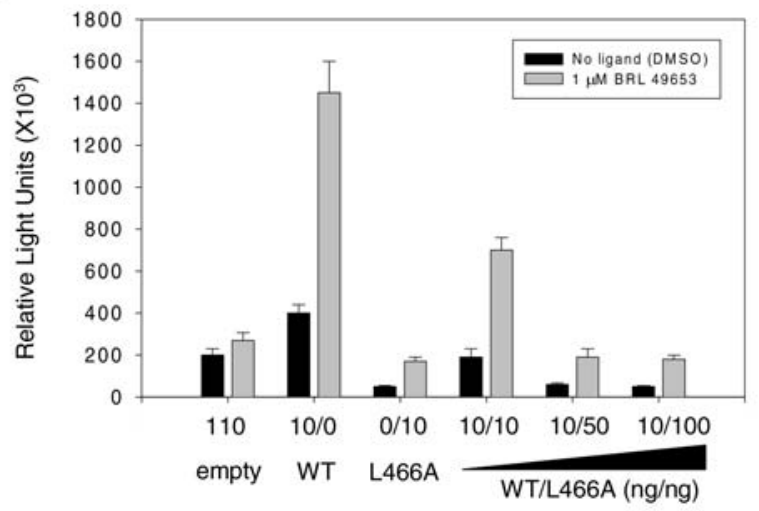

$\mathrm{B}$

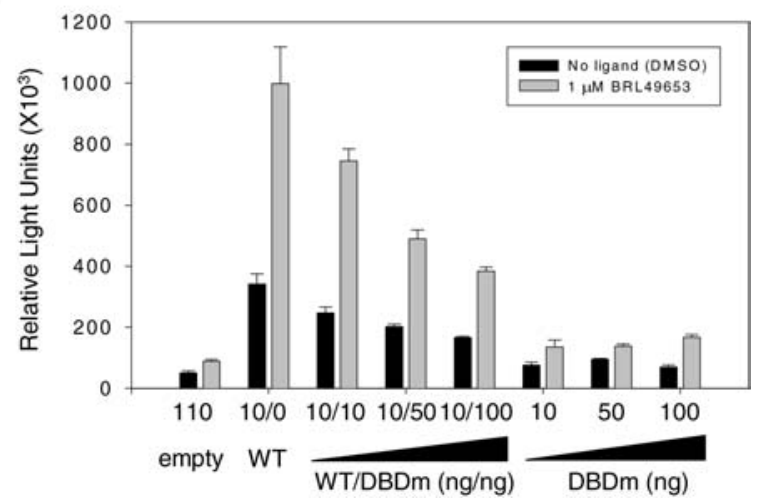

Fig. 4A, B. Dominant negative activity of the L466A mutant. (A) The L4664 mutant exerts a dominant negative effect; coexpression with an equal concentration of WT reduces transcriptional activity by $50 \%$. (B) A five-fold excess of the DBDm is required to reduce wild-type PPAR $\gamma$ activity to $50 \%$ as compared to an equal concentration of the L466A mutant. TSA cells were transfected with $500 \mathrm{ng} /$ well of $2 \mathrm{X}$ PPRE-TK-Luc and the indicated PPAR $\gamma$ constructs (WT, L466A, and DBDm). Increasing concentrations of the L466A and DBDm DNA were added to $10 \mathrm{ng} /$ well of PPAR $\gamma$. Increasing pCMX empty vector (up to $100 \mathrm{ng}$ ) was added to compensate for increased total DNA concentration. Transfection and luciferase assays were carried out

at position 466 of PPAR $\gamma$ is the second $\mathrm{L}$ in the characteristic nuclear receptor signature motif (LXXLL motif) of the well-conserved AF-2, a region known to be important for interaction with coactivators. The empty Gal4 vector did not activate the UAS reporter with VP16 vectors containing the interaction domains of either the PBP or SRC-1 coactivators. When coexpressed, PPAR $\gamma$ WT interacted with both PBP and SRC-1. This interaction was further enhanced, approximately two-fold and four-fold respectively, by the addition of $1 \mu \mathrm{mol} / \mathrm{l} \mathrm{BRL}$. PBP interacted weakly with L466A and SRC-1 did not interact with the L466A mutant, consistent with X-ray crystallographic data showing that this Leu residue is critical for the interaction with SRC-1.

Helix 12, containing the AF-2 domain, serves to trigger the release of corepressors from members of 
A
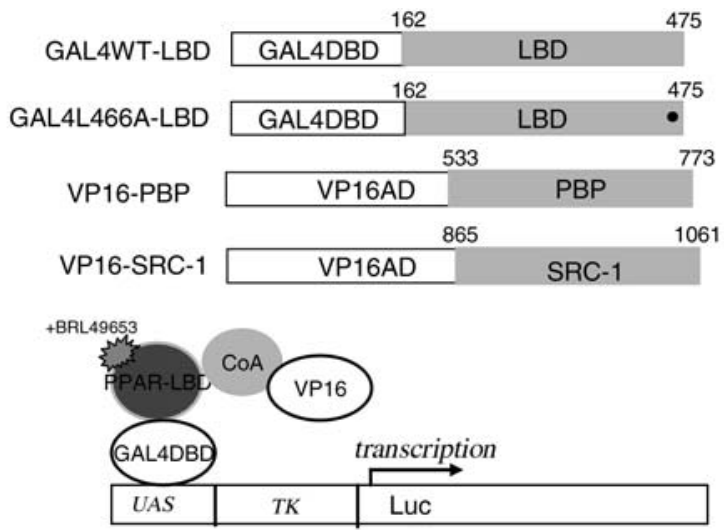

B

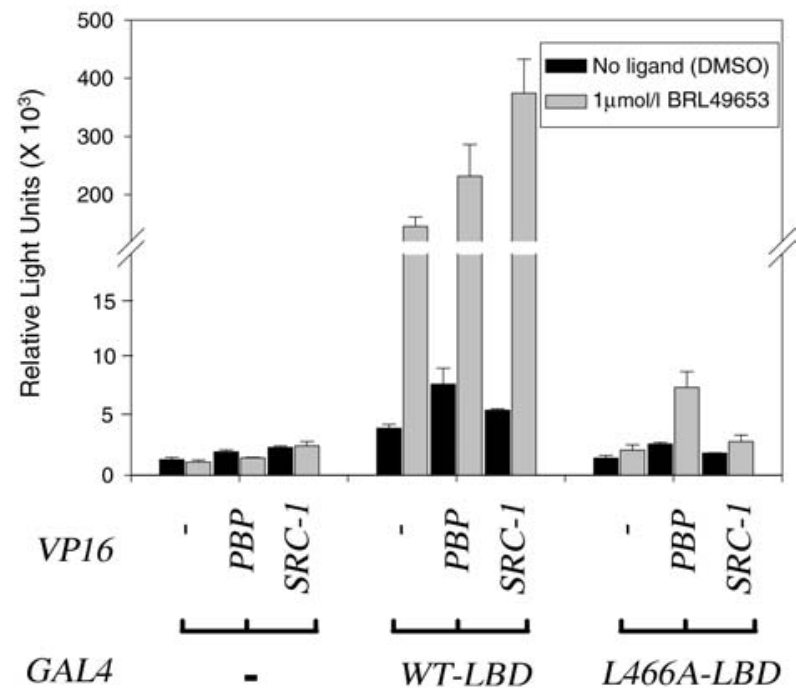

Fig. 5A, B. Defective recruitment of coactivators to the L466A mutant. (A) Schematic illustration of Gal4-PPAR $\gamma$ fusion proteins, WT or L466A mutant (O), and VP16-ID fusion proteins, with the interaction domains of either the SRC-1 or PBP coactivators. Additionally, a depiction of the mammalian two-hybrid system is shown. (B) The Gal4WT-LBD or Gal4L466ALBD (50 ng/well) and VP16-PBP or VP16SRC-1 (50 ng/well) were cotransfected into TSA cells with the UAS-E1b-TATALuc reporter (500 ng/well). Equivalent amounts of Gal4 and VP16 were used as controls

nuclear hormone receptors. Mutation or deletion of helix 12 of thyroid receptors and retinoic acid receptors enhances the interaction with corepressors and reduces the release of the corepressors after ligand binding. As the LBD of the L466A mutant showed suppression of basal receptor activity, additional mammalian two-hybrid studies were used to test the hypothesis that the L466A mutant shows increased binding and impaired release of corepressors after the addition of ligand. This series of transient transfections utilized VP16AD and Gal4DBD vectors containing the LBDs of various PPAR $\gamma$ constructs and the interaction domains (IDs) of corepressors, respectively (Fig. 6A). The IDs containing the $\varphi \times x \varphi \varphi$ motifs (where $\varphi=$ hydrophobic amino acid) of hSMRT and mNCoR were inserted into Gal4 DNA binding domain vectors either alone (Gal4-ID1, Gal4-ID2) or together (Gal4-
ID1+ID2). The VP16-LBDs of either WT or L466A were cotransfected with the Gal4-IDs of either hSMRT or mNCoR into TSA201 cells with the UASluciferase reporter. ID1, but not ID2, of both hSMRT and $\mathrm{mNCoR}$ activated transcription of the reporter (Fig. 6B) when cells were cotransfected with Gal4WT. This suggests that ID1 is necessary for the interaction between PPAR $\gamma$ and corepressors. However, longer regions of hSMRT, but not $\mathrm{mNCoR}$, containing both ID1 and ID2, increased transcription approximately ten-fold more than ID1 alone (Fig. 6B). This finding suggests that the corepressor regions analyzed bind with different affinities to PPAR $\gamma$. The L466A mutant showed a stronger interaction than wild-type PPAR $\gamma$ with the ID1s of both hSMRT and mNCoR in the absence of ligand. The corepressor ID1 domains were dissociated from the PPAR $\gamma$ constructs in a ligand-dependent manner (Fig. 6C). However, the L466A mutant demonstrated greatly impaired liganddependent corepressor release as evidenced by the decreased reduction of transcription with ligand (Fig. 6B). Mutation of a single amino acid in the $\varphi \times x \varphi \varphi$ motif of the ID1 of both corepressors (ID1M) completely abolished the ability of the corepressors to interact with the LBD of the PPAR $\gamma$ constructs. Consistent with the proposed dominant negative action of the L466A mutant, the ID1s of both hSMRT and $\mathrm{mNCoR}$ have a stronger interaction with mutant than wild-type PPAR $\gamma$ and delayed dissociation upon addition of an increasing concentration of ligand (Fig. 6C). Adipogenesis is impaired with the adenovirus-directed PPAR $\gamma$ dominant negative mutant, Ad-L466A Adipogenesis was studied to investigate the cellular function of the L466A mutant. To this end, the murine 3T3-L1 preadipocyte cell line was infected with equal amounts of adenovirus directed $\beta$-galactosidase (AdGal), PPAR $\gamma$ WT (AdWT) or PPAR $\gamma$ mutants (AdL466A, AdDBDm). The titration of adenoviral constructs necessary to achieve a transduction efficiency of 95 to $100 \%$ was calculated to be $1000 \mathrm{Pfu}$ per cell. Equivalent protein expression at $1000 \mathrm{Pfu}$ per cell of each adenovirus was confirmed by Western blotting. It has been previously shown that adenovirus gene expression driven by a CMV promoter peaks 3 to 5 days after infection [37]. Thereafter, gene expression decreases, but is maintained up to 21 days postinfection. An unexpected lipid accumulation was observed by Oil red-O staining in 3T3-L1 preadipocytes infected with AdWT without the PPAR $\gamma$ ligand BRL (Fig. 7B). The PPAR $\gamma$ infected cells adopted the morphology characteristic of adipocytes, whereas control 3T3-L1 cells infected with AdGal did not undergo differentiation (Fig. 7A, B). Preadipocytes infected with either AdL466A or AdDBDm exhibited limited lipid accumulation in the absence of ligand, and most of the cells remained in an undifferentiated state (Fig. 7C, D). TZDs alone, including BRL, have been reported to induce adipogenesis in 3T3-L1 cells. In order to confirm 
A

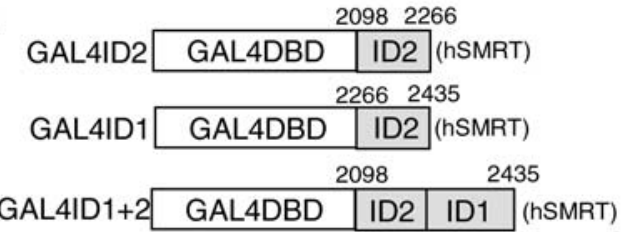

\begin{tabular}{rlcr}
\multicolumn{2}{c}{162} & 475 \\
\cline { 4 - 4 } VP16-WT & VP16AD & LBD \\
\cline { 4 - 4 } VP16-L466A & VP16AD & LBD & $\bullet 75$
\end{tabular}

B

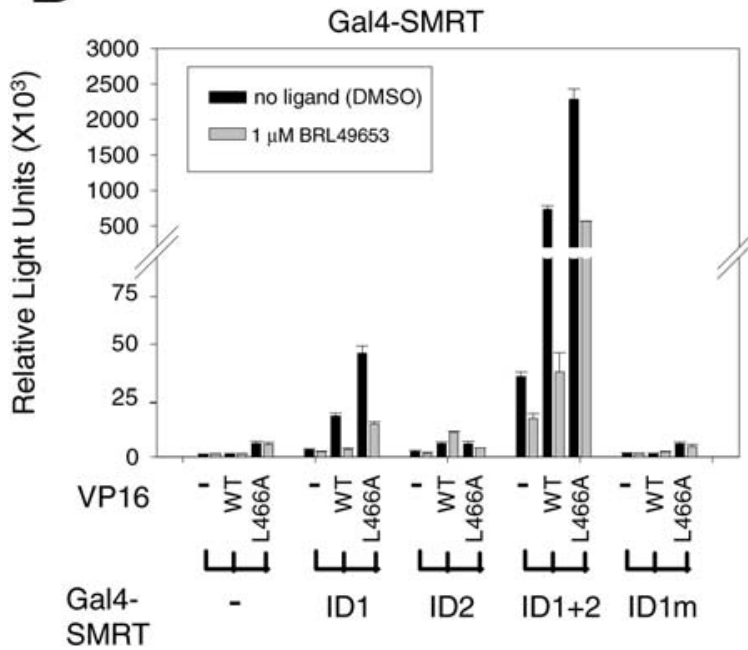

SMRT

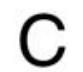

ำ

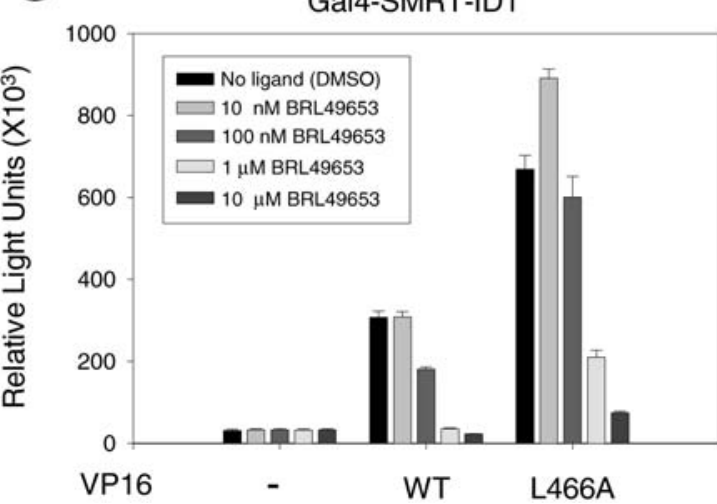

Fig. 6A-C. Enhanced interaction and defective release of corepressors from the L466A mutant. (A) Left panel: schematic illustration of Gal4 vectors (Gal4SMRT-IDs, Gal4NCoR-IDs), VP16 vectors (VP16WT-LBD,VP16L466A-LBD), and mammalian two-hybrid system. The reference nucleotides for the hSMRT constructs are depicted. Right panel: corepressors (CoRs) interact with PPAR $\gamma$ constructs without ligand. (B) The hSMRT and mNCoR corepressor ID1 domains interact more avidly with the L466A mutant than with WT. The individual Gal4-ID1, ID2 and ID1+2 fusion constructs of hSMRT (left panel) and mNCoR (right panel) were cotransfected (50 ng/well) into TSA cells with VP16 constructs $(50 \mathrm{ng} /$ well) including VP16 empty vector, VP16WT-LBD, and VP16L46-
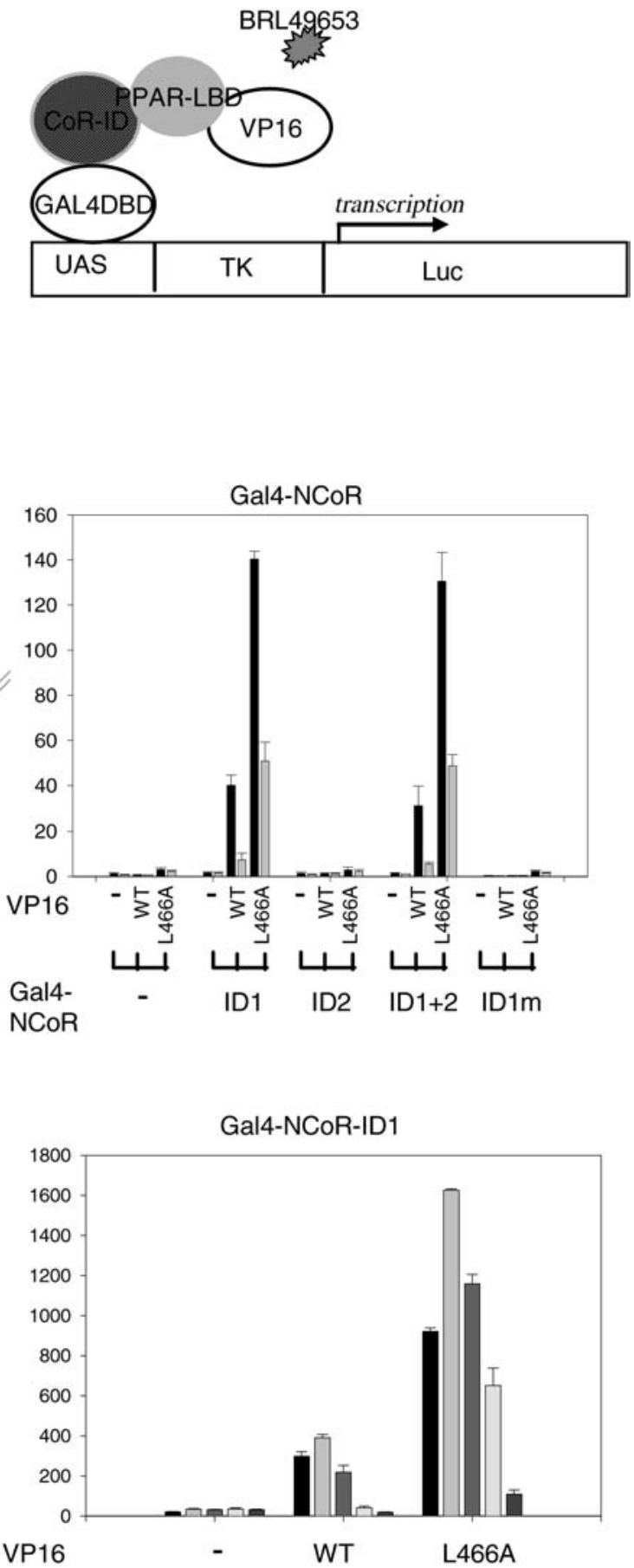

6A-LBD, and with the UAS-E1b-TATA-Luc reporter $(500 \mathrm{ng} /$ well). Eighteen hours post-transfection, $1 \mu \mathrm{mol} / \mathrm{l}$ of BRL49653 or DMSO (control) was added with fresh media. (C) Defective dissociation of corepressors from the L466A mutant in a ligand-dependent manner. Equivalent amounts of Gal4 constructs (Gal4SMRT-ID1 or Gal4NCoR-ID1) and VP16 constructs (50 ng/well) were cotransfected into TSA cells with the UAS-E1b-TATA-luc reporter $(500 \mathrm{ng} / \mathrm{well})$. Eighteen hours post-transfection, increasing concentrations of BRL49653, from $10 \mathrm{nmol} / \mathrm{l}$ to $10 \mu \mathrm{mol} / \mathrm{l}$, were added to the cells. The cells were incubated for an additional $24 \mathrm{~h}$, and then harvested for luciferase assays 

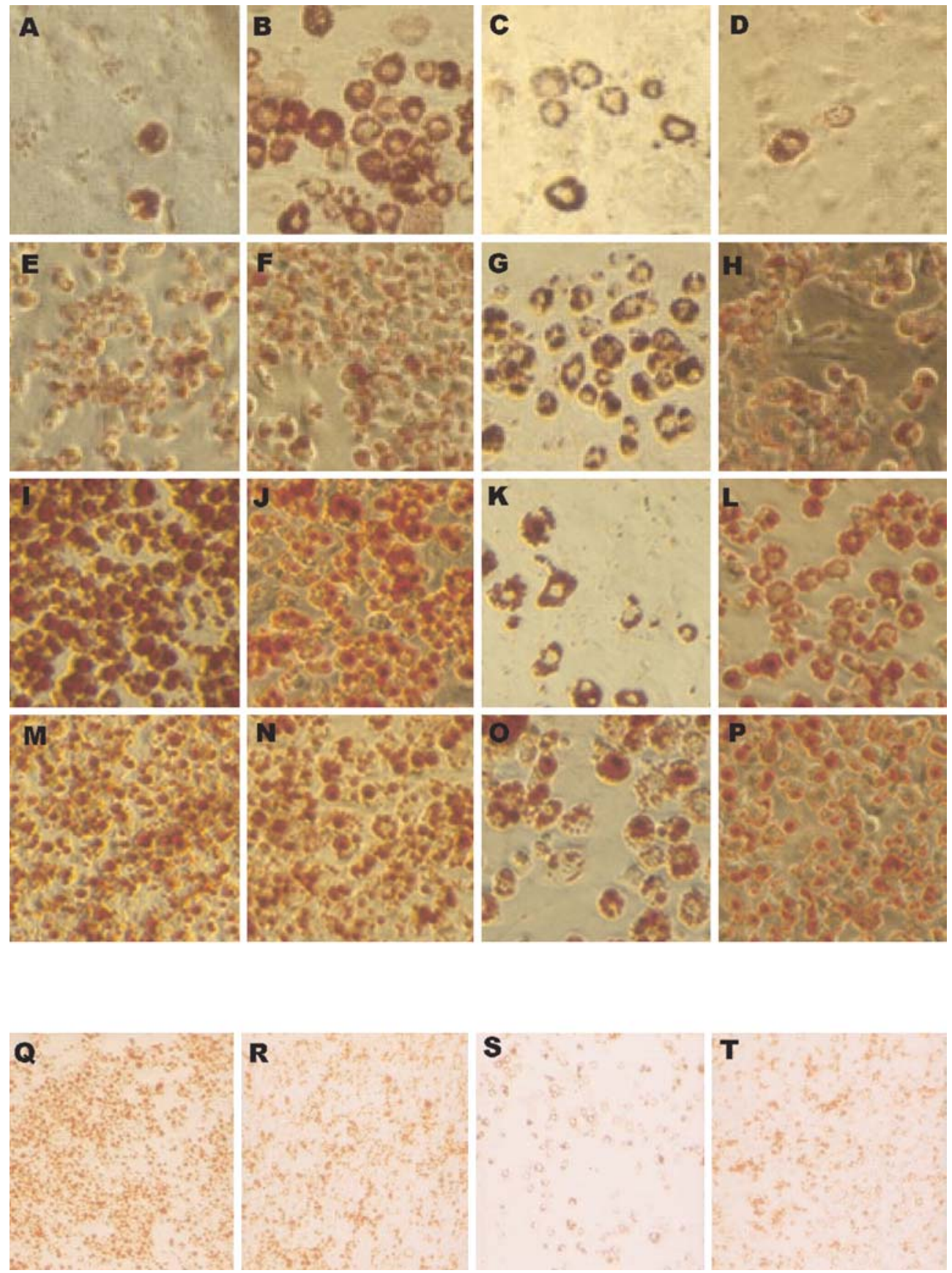

Fig. 7A-T. Expression of adenovirus-directed PPAR $\gamma$ constructs in 3T3-L1 preadipocytes. AdWT (B, F, J, N), $\operatorname{AdL466A}(\mathbf{C}, \mathbf{G}, \mathbf{K} . \mathbf{O})$, and $\operatorname{AdDBDm}(\mathbf{D}, \mathbf{H}, \mathbf{L}, \mathbf{P})(1000$ $\mathrm{Pfu} /$ cell) were infected at 30-40\% confluency of 3T3-L1 cells. The same amount of AdGal was infected as a control (A, E, I, M). Three days post-infection, cells were induced to differentiate with the addition of MDI (MIX, Dex, and Insulin) alone $(\mathbf{I}, \mathbf{J}, \mathbf{K}, \mathbf{L})$, BRL 49653 alone $(\mathbf{E}, \mathbf{F}, \mathbf{G}, \mathbf{H})$, or MDI and BRL49653 together (M, N, O, P). Several wells of infected cells were given no treatment $(\mathbf{A}, \mathbf{B}, \mathbf{C}, \mathbf{D})$. Two days post-induction, and every 2 days for 8 days total, the media was replaced with fresh media (A-D; I-L) or with fresh media containing $1 \mu \mathrm{M}$ BRL 49653 (E-H; M-P). Cells were gently washed and stained with Oil-Red $\mathrm{O}$ on the $8^{\text {th }}$ day of differentiation. Panels A-P are shown at 400X magnification. Panels Q-T are shown at $100 \times$ magnification and represent enlarged fields of view for Panels $\mathbf{I}-\mathbf{L}$

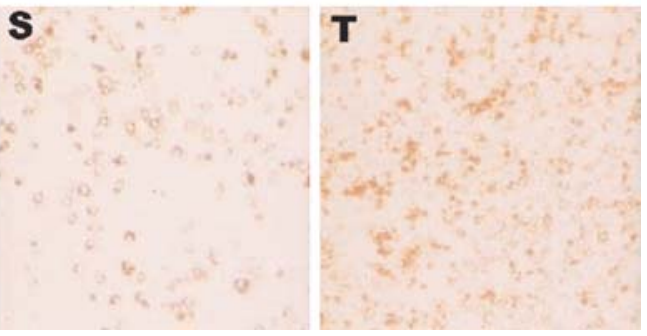

BRL-induced adipogenesis in 3T3-L1 cells, AdGal infected 3T3-L1 cells were treated with BRL every $48 \mathrm{~h}$ for 8 days (Fig. 7E). Marginal lipid accumulation was observed in these cells when compared to those that received no ligand treatment (Fig. 7A, E). Infection of AdWT into 3T3-L1 cells and subsequent treatment with ligand led to increased adipocyte formation and lipid accumulation (Fig. 7F). However, the morphological characteristics of the adenovirus-infected adipocytes treated with BRL differed from those of infected cells that did not receive ligand. Adipocytes treated with ligand were smaller in size and contained less lipid than those that received no ligand.

To evaluate whether PPAR $\gamma$ mutants are capable of blocking ligand-induced adipogenesis, the 3T3-L1 cell 
A

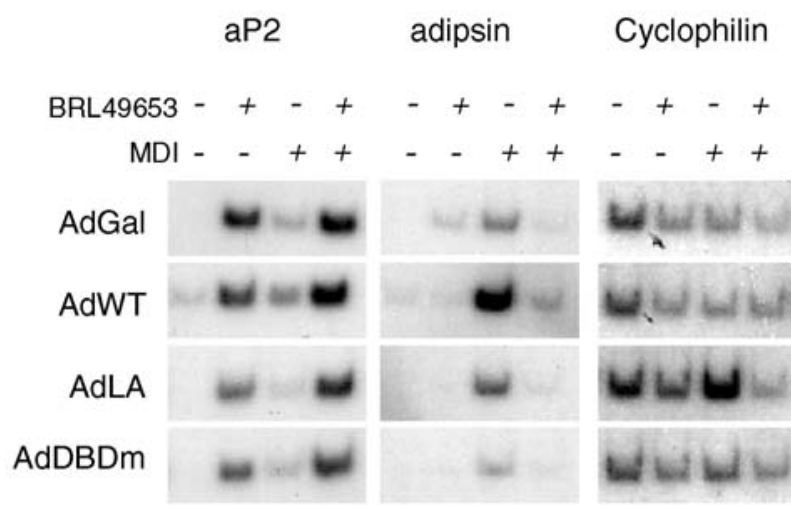

B

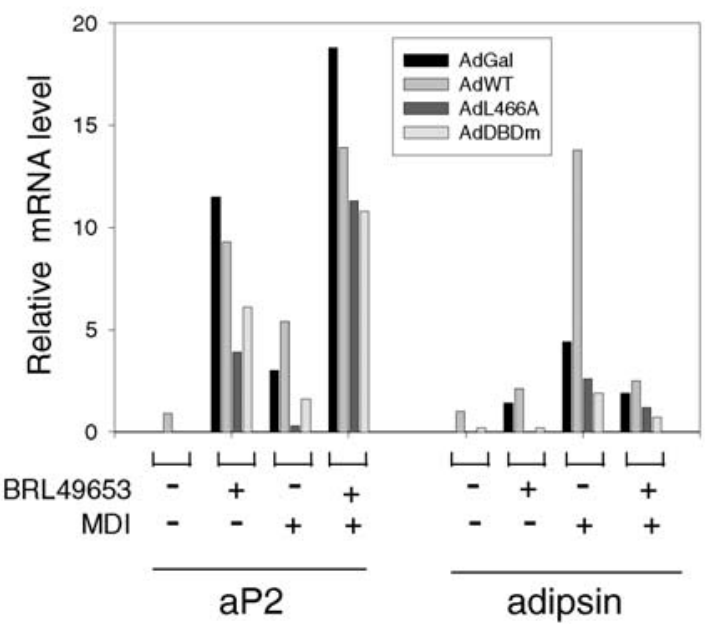

Fig. 8A, B. Expression of adipocyte-specific markers in 3T3-L1 cells. (A) The L466A mutant reduces expression of aP2 and adipsin in differentiated 3T3-L1 cells. Total RNA was isolated on the $8^{\text {th }}$ day of differentiation. Isolated RNA was subjected to the semi-quantitative RT-PCR using specific primers for $\mathrm{aP} 2$, adipsin, and cyclophilin as a control. PCR products were separated by $6 \%$ non-denaturing polyacrylamide gel electrophoresis and autoradiographed. (B) aP2 and adipsin expression levels were normalized to cyclophilin using densitometry

line was infected with either AdL466A or AdDBDm. Those cells infected with either AdL466A or AdDBDm and given BRL were fewer in number and showed less lipid accumulation (TG content: $60.5 \pm 2.0 \mathrm{mg} / \mathrm{dl}$ and $66.8 \pm 4.2 \mathrm{mg} / \mathrm{dl}$, respectively) than both the AdWT infected cells (TG content: 91.6 $\pm 2.6 \mathrm{mg} / \mathrm{dL}$ ) and the control group (TG content: $97.8 \pm 4.2 \mathrm{mg} / \mathrm{dL}$ ) (Fig. 7E-H). However, the size and number of lipid vesicles in individual adipocytes was greater in the AdL466A group than in the control group. Morphologically, the lipid accumulation pattern and shape of adipocytes in the AdL466A cells given ligand (Fig. 7G) was similar to that in the AdWT cells that were not treated with ligand (Fig. 7B). The lower degree of lipid accumulation in AdL466A infected cells given ligand as compared to AdWT infected cells that did not receive ligand is consistent with the in vitro transfection data (Fig. 1B). The morphology of the adipocytes from the AdDBDm group treated with BRL also differed from that of either the AdGal control or AdL466A infected cells (Fig. $7 \mathrm{H})$.

A differentiation cocktail commonly used to induce 3T3-L1 cells into adipocytes is referred to as MDI and contains methylisobutylxanthine, dexamethasone, and insulin. In the next series of experiments, AdL466A or AdDBDm were infected into 3T3-L1 cells induced to differentiate by MDI treatment. The MDI cocktail itself significantly induced adipocyte formation as compared to BRL treatment alone in Ad-Gal infected cells (Fig. 7, panels I and E). Treatment with a combination of MDI and BRL gave rise to an increase in number and a decrease in size of adipocytes, as compared to those cells treated solely with MDI (Fig. 7, panel M). Lipid accumulation in individual MDIinduced adipocytes was more pronounced in the absence of further treatment with BRL. Further infection with AdWT did not increase adipocyte formation, but rather these cells underwent less adipogenesis. When 3T3-L1 cells were infected with AdL466A and induced to differentiate by MDI, both the number of adipocytes formed and lipid accumulation wherein were dramatically reduced (Fig. 7, panel K). This reduction was comparable to that achieved with AdL466A-infected cells that received neither MDI nor BRL treatment (Fig. 7, panel C). This result clearly demonstrates that AdL466A can inhibit MDI-induced adipogenesis (Fig. 7, panel K). Infection with AdDBDm (Fig. 7, panel L and P) did not inhibit MDIinduced adipogenesis to the extent seen with infection by AdL466A (Fig. 7, $\mathrm{K}$ and O), a result consistent with the transfection data (see Fig. 4B). These functional studies confirm that L466A is a strong dominant negative form of PPAR $\gamma$.

Adenovirus-directed expression of the L466A mutant blocks PPAR $\gamma$ upregulation of the adipocyte-specific genes, aP2 and adipsin. To investigate the regulation of genes controlling the adipocyte phenotype of adenoviral-infected 3T3-L1 cells, we used 32P-labelled semi-quantitative RT-PCR of known PPAR $\gamma$ target genes in adipocytes. Total RNA was isolated from Ad-expressing cells after 8 days post-confluent culture using three different conditions. The expression of $\mathrm{aP} 2$ and adipsin differed based on the differentiation conditions, and undifferentiated 3T3-L1 cells infected with AdGal did not have detectable expression of either gene product (Fig. 8A). BRL treatment induced the expression of $\mathrm{aP2}$ with or without prior MDI induction. However, the expression of aP2 in MDIinduced adipocytes was lower than that of BRL-induced adipocytes. The expression pattern of adipsin was just the opposite, as adipsin was increased in the adipocytes, but MDI-induced adipocytes had a higher expression relative to BRL-induced adipocytes. This 
is consistent with a report that categorized adipsin as a cluster27 gene, upregulated by MDI and downregulated by TZD in adipocytes. Overexpression of PPAR $\gamma$ WT in 3T3-L1 cells was sufficient for aP2 expression consistent with adipocyte morphology (Fig. 7B). The addition of BRL to these PPAR $\gamma$-over-expressing cells further increased aP2 expression. Those cells infected with AdL466A or AdDBDm and treated with BRL showed reduced aP2 expression to approximately $50 \%$ the expression seen in Ad-WT or Ad-Gal infected cells treated with BRL. The induction of adipogenesis by MDI was sufficient to induce aP2 expression. Combination of MDI-induction and BRL treatment resulted in a similar pattern of aP2 expression as BRL treatment alone. The expression of adipsin in MDI-induced cells infected with AdL466A or AdDBDm was decreased relative to those cells infected with AdWT or AdGal. The further addition of BRL to MDIinduced adipocytes led to sharp reductions in adipsin expression for all infected cells. Cyclophilin was used as a control in the RT-PCR studies. AdL466A infection clearly blocks the up-regulation of both $\mathrm{aP} 2$ and adipsin (Fig. 8B), consistent with the inhibition of adipogenesis by this dominant negative PPAR $\gamma$ mutant.

\section{Discussion}

We have shown that the mouse PPAR $\gamma$ L466A mutant interferes with the differentiation of 3T3-L1 cells into adipocytes. Co-expression of equivalent amounts of the L466A mutant and wild-type PPAR $\gamma$ reduced the transcriptional activity of wild-type PPAR $\gamma$ by $50 \%$. This mutant exhibits altered cofactor recruitment and release, and strongly inhibits the adipogenesis of 3T3-L1 cells, whether induced by a differentiation cocktail (MDI), or a PPAR $\gamma$ thiazolidinedione ligand (BRL49653). A second PPAR $\gamma$ mutant, a double point mutant in the DBD (E127G/G129/S, DBDm), is unable to bind to a consensus PPRE and it less effectively inhibits wild-type PPAR $\gamma$. We initially designed the DBDm as a negative control, anticipating that DNA binding would be required for dominant negative inhibition, as is the case for mutant thyroid hormone receptors [29, 43]. However, the DBDm exerts some dominant negative activity, particularly at high concentrations. A comparison of the morphology of 3T3-L1 adipocytes infected with adenoviral-directed L466A or DBDm indicates that the DBDm is less effective at blocking both BRL- and MDI-induced adipogenesis. However, the DBDm inhibits gene expression of two markers of adipogenesis, aP2 and adipsin, as potently as the L466A mutant. Although not the major focus of this study, this feature could be of interest, as it might reflect titration of limiting coactivators [51, 52], or interactions with components of the PPAR $\gamma$ pathway proximal to DNA binding $[49,53$, 54]. The MDI differentiation cocktail activates the
PI3 K and PKA signaling cascades and leads to activation of transcription factors involved in adipogenesis [55]. Thus, it is likely that both the L466A and DBD mutants possess dominant negative activity, but use different mechanisms of action to achieve this effect. In this study we chose to focus on the dominant negative behaviour of the L466A mutant, likely due to its altered cofactor recruitment profile.

Increasing evidence suggests that the progression of adipogenesis is regulated by PPAR $\gamma$ cofactor availability. The exchange of cofactors, corepressors to coactivators, with ligand, has been well studied for both the retinoic acid receptor and thyroid receptor families [9]. Without ligand, corepressors such as NCoR and SMRT bind to helix 12 of these receptors through their interaction domains (IDs). While the interaction of PPAR $\gamma$ with coactivators has been characterized extensively $[8,12,13,14,15,16]$, its interaction with corepressors has not been well studied. Our findings, and two other studies $[27,56]$, show that PPAR $\gamma$ interacts with corepressors without ligand. Mammalian two-hybrid studies show that PPAR $\gamma$ prefers to interact with ID1 of both the mNCoR and hSMRT corepressors. This study shows that corepressors bind with increased affinity through their ID1s to the L466A dominant negative mutant, when compared to their binding to wild-type PPAR $\gamma$. Additionally, the dissociation of the mNCoR or hSMRT ID1 from the L466A mutant upon the addition of PPAR $\gamma$ ligand required a 100 -fold increase in ligand concentration compared to the dissociation from wild-type PPAR $\gamma$. The altered corepressor association profile is likely to be an important feature of the dominant negative action of the L466A mutant.

A dominant negative double point mutant, L468A/E471A, has been previously reported in human PPAR $\gamma[27,28]$. The location of the L466A mutation in mouse PPAR $\gamma$ corresponds to the L468A mutation in human PPAR $\gamma$, as the human protein contains two additional amino acids at amino-terminus. Others [27] incorporated a second mutation of the glutamate residue at position 471, a residue that is highly conserved throughout helix 12 of the nuclear receptor family. The L466A mutation presented here confirms their finding that mutation of helix 12 creates a PPAR $\gamma$ construct with strong dominant negative activity. The single L466A mutation is sufficient to inhibit adipogenesis as well as PPAR $\gamma$-target gene regulation. The leucine residue at position 466 of the AF-2, part of the nuclear receptor LXXLL motif, clearly plays an important role in the exchange of cofactors.

In addition to its role in the regulation of adipogenesis, PPAR $\gamma$ has been implicated in glucose homeostasis and insulin sensitivity. While the role of PPAR $\gamma$ as a determinant factor in adipogenesis both in vitro and in vivo has been well characterized, the insulin sensitizing function of PPAR $\gamma$ remains unclear. The activation of PPAR $\gamma$ by TZDs improves insulin sensitivity 
and lowers blood glucose values, but results in body weight gain $[23,24]$. The reduction of PPAR $\gamma$ function by dominant negative mutations (P465L and V290M) in human PPAR $\gamma$ is associated with severe insulin resistance and diabetes [26]. However, the moderate reduction of PPAR $\gamma$ function by the Pro12Ala PPAR $\gamma$ polymorphism in human mutations improves insulin sensitivity and lowers body mass index [57]. Mouse studies are consistent with improved insulin sensitivity in the setting of reduced PPAR $\gamma$ function. PPAR $\gamma$ heterozygous knock-out mice [18] show increased insulin sensitivity and inhibition of high-fat diet-induced obesity $[58,59,60]$. Interestingly, further inhibition of PPAR $\gamma$ in the heterozygous PPAR $\gamma$ deficient mice by treatment with PPAR or RXR antagonists leads to the re-emergence of insulin resistance [25]. Thus, the insulin sensitizing action of PPAR $\gamma$ in vivo could be dose-dependent, and the tissues that facilitate glucose homeostasis such as adipocytes, muscle and liver might be sensitive to the precise amount of active PPAR $\gamma$. Improvement of insulin sensitivity by pharmacological activation or genetic reduction of PPAR $\gamma$ in mouse could be explained by the prevention of adipocyte hypertrophy and decreased free fatty acids in muscle and liver [25].

The reduction of active PPAR $\gamma$ function through the use of a dominant negative mutant in vivo would be useful to better understand the role of PPAR $\gamma$ in insulin sensitivity. To this end, we plan to "knock-in" the L466A mutation in the mouse to assess its effects on PPAR $\gamma$ in vivo. The heterozygous model will provide insight into the mechanism by which PPAR $\gamma$ regulates adipogenesis and insulin sensitivity.

\section{References}

1. Rosen ED, Spiegelman BM (2001) PPARgamma: a nuclear regulator of metabolism, differentiation, and cell growth. J Biol Chem 276:37731-37734

2. Auwerx J (1999) PPARgamma, the ultimate thrifty gene. Diabetologia 42:1033-1049

3. Rosen ED, Walkey CJ, Puigserver P, Spiegelman BM (2000) Transcriptional regulation of adipogenesis. Genes Dev 14:1293-1307

4. Tontonoz P, Graves R, Budavari AI et al. (1994) Adipocyte specific transcription factor ARF6 is a heterodimeric complex of two nuclear hormone receptors, PPAR $\gamma$ and RXR $\alpha$. Nucleic Acids Res 22:5628-5634

5. Juge-Aubry C, Pernin A, Favez T et al. (1997) DNA binding properties of proxisome proliferator-activated receptor subtypes on various natural peroxisome proliferator response elements. J Biol Chem 272:25252-25259

6. Evans RM (1988) The steroid and thyroid hormone receptor superfamily. Science 240:889-895

7. Westin S, Kurokawa R, Nolte RT et al. (1998) Interactions controlling the assembly of nuclear-receptor heterodimers and co-activators. Nature 395:199-202

8. Nolte RT, Wisely GB, Westin S et al. (1998) Ligand binding and co-activator assembly of the peroxisome proliferator-activated receptor-gamma. Nature 395:137-143
9. Lin BC, Hong SH, Krig S, Yoh SM, Privalsky ML (1997) A confirmational switch in nuclear hormone receptors is involved in coupling hormone binding to corepressor release. Mol Cell Biol 17:6131-6138

10. Lavinski RM, Jepsen K, Heinzel T et al. (1998) Diverse signaling pathways modulate nuclear receptor recruitment of N-CoR and SMRT complexes. Proc Natl Acad Sci USA 95:2920-2925

11. Zamir I, Zhang J, Lazar MA (1997) Stoichiometric and steric principles governing repression by nuclear hormone receptor. Genes Dev 11:835-846

12. Gelman L, Zhou G, Fajas L, Raspe E, Fruchart JC, Auwerx J (1999) p300 interacts with the $\mathrm{N}$ - and C-terminal part of PPAR gamma2 in a ligand-independent and -dependent manner respectively. J Biol Chem 274:7681-7688

13. Takahashi N, Kawada T, Yamamoto T et al.(2002) Overexpression and ribozyme-mediated targeting of transcriptional coactivators CREB-binding protein and p300 revealed their indispensable roles in adipocyte differentiation through the regulation of peroxisome proliferator-activated receptor gamma. J Biol Chem 277:16906-16912

14. Zhu Y, Qi C, Jain S, Rao MS, Reddy JK (1997) Isolation and characterization of $\mathrm{PBP}$, a protein that interacts with peroxisome proliferator-activated receptor. J Biol Chem 272:25500-25506

15. Ge K, Guermah M, Yuan CX et al. (2002) Transcription coactivator TRAP220 is required for PPARgamma2-stimulated adipogenesis. Nature 417:563-567

16. Puigserver P, Wu Z, Park CW, Graves R, Wright M, Spiegelman BM (1998) A cold-inducible coactivator of nuclear receptors linked to adaptive thermogenesis. Cell 92:829-839

17. Kubota N, Terauchi Y, Miki H et al. (1999) PPAR gamma mediates high-fat diet-induced adipocyte hypertrophy and insulin resistance. Mol Cell 4:597-609

18. Barak Y, Nelson MC, Ong ES et al. (1999) PPAR gamma is required for placental, cardiac, and adipose tissue development. Mol Cell 4:585-595

19. Rosen ED, Sarraf P, Troy AE et al. (1999) PPAR gamma is required for the differentiation of adipose tissue in vivo and in vitro. Mol Cell 4:611-617

20. Rosen ED, Hsu CH, Wang X et al. (2002) C/EBPalpha induces adipogenesis through PPARgamma: a unified pathway. Genes Dev 16:22-26

21. Mudaliar S, Henry RR (2001) New oral therapies for type 2 diabetes mellitus; The glitazones or insulin sensitizers. Annu Rev Med 52:239-257

22. Lehmann JM, Moore LB, Smith-Oliver TA, Wilkson WO, Willson TM, Klier SA (1995) An antidiabetic thiazolidinedione is a high affinity ligand for peroxisome proliferator-activated receptor $\gamma$ (PPAR $\gamma$ ). J Biol Chem 270:12953-12956

23. Kletzien RF, Clarke SD, Ulrich RG (1992) Enhancement of adipocyte differentiation by an insulin-sensitizing agent. Mol Pharmacol 41:393-398

24. Sandouk T, Reda D, Hofman C (1993) Antidiabetic agent pioglitazone enhances adipocyte differentiation of 3T3F442A cells. Am J Physiol 264:C1600-1608

25. Yamauchi T, Kamon J, Waki H et al. (2001) The mechanisms by which both heterozygous peroxisome proliferator- activated receptor gamma (PPARgamma) deficiency and PPARgamma agonist improve insulin resistance. J Biol Chem 276:41245-41254

26. Barroso I, Gurnell M, Crowly VEF et al. (1999) Dominant negative mutations in human PPAR $\gamma$ associated with severe insulin resistance, diabetes mellitus and hypertension. Nature 402:880-883

27. Gurnell M, Wentworth JM, Agostini M et al. (2000) A dominant-negative peroxisome proliferator-activated recep- 
tor $\gamma(\operatorname{PPAR} \gamma)$ mutant is a constitutive repressor and inhibits PPAR $\gamma$-mediated adipogenesis. J Biol Chem 275: 5754-5759

28. Nugent C, Prins JB, Whitehead JP, Savage D, Wentworth JM, Chatterjee VK, O'Rahilly S (2001) Potentiation of glucose uptake in 3T3-L1 adipocytes by PPAR gamma agonists is maintained in cells expressing a PPAR gamma dominant-negative mutant: evidence for selectivity in the downstream responses to PPAR gamma activation. Mol Endocrinol 15:1729-1738

29. Collingwood TN, Rajanayagam O, Adams M et al. (1997) A natural transactivation mutation in the thyroid hormone beta receptor: impaired interaction with putative transcriptional mediators. Proc Natl Acad Sci USA 94:248-253

30. Umesono K, Murakami KK, Thompson CC, Evans RM (1991) Direct repeat as selective response elements for the thyroid hormone, retinoic acid, and vitamine D3 receptors. Cell 65:1255-1266

31. Sadowski I, Ma J, Tiezenberg S, Ptashne M (1988) Gal4VP16 is an unusally potent transcriptional activator. Nature 335:563-564

32. Sadowski I, Ptashne M (1989) GAL4 is phosphorylated as a consequence of transcriptional activation. Nucleic Acids Res 17:7539

33. Ito M, Yu RN, Jameson JL (1998) Steroidogenic factor-1 contains a carboxy-terminal transcriptinal activation domain that interacts with steroid receptor coactivator-1. Mol Endocrinol 12:290-301

34. Ito M, Park Y, Weck J, Mayo KE, Jameson JL (2000) Synergistic activation of inhibin alpha by steroidogenic factor-1 and cyclic adenosine $3^{\prime}, 5^{\prime}$-monophosphate. Mol Endocrinol 14:66-81

35. Tagami T, Lutz W, Kumar R, Jameson JL (1998) The interaction of vitamine $\mathrm{D}$ receptor with nuclear receptor corepressors and coactivators. Biochem Biophys Res Commun 253:358-363

36. Lee EJ, Anderson LM, Thimmapaya B, Jameson JL (1999) Targeted expression of toxic genes directed by pituitary hormone promoters: a potential strategy for adenovirusmediated gene therapy of pituitary tumors. J Clin Endocrinol Metab 84:786-794

37. Lee EJ, Thimmapaya B, Jameson JL (2000) Stereotactic injection of adenoviral vectors that target gene expression to specific pituitary cell types: implications for gene therapy. Neurosurgery 46:1461-1469

38. Jakacka M, Ito M, Weiss J, Chien PY, Gehm BD, Jameson JL (2001) Estrogen receptor binding to DNA is not required for its activity through the nonclassical AP1 pathway. J Biol Chem 276:13615-13621

39. Green H, Kehinde O (1976) Spontaneous heritable changes leading increased adipose conversion in 3T3 cells. Cell 7:105-113

40. Green H, Kehinde O (1974) Sublines of mouse 3T3 cells that accumulate lipid. Cell 1:113-116

41. Wang ZJ, Jeffs B, Ito M, Achermann JC, Yu RN, Hales DB, Jameson JL (2001) Aromatase (Cyp19) expression is up-regulated by targeted disruption of Dax1. Proc Natl Acad Sci USA 98:7988-7993

42. Savador LM, Park Y, Cottom J, Maizels ET, Jones JC, Schillace RC, Carr DW, Cheung P, Allis CD, Jameson JL, Hunzicker-Dunn M (2001) Follicle-stimulating hormone stimulates protein kinase A-mediated histone $\mathrm{H} 3$ phosphorylation and acetylation leading to select gene activation in ovarian granulosa cells. J Biol Chem 276:40146-40155
43. Tagami T, Gu WX, Peairs PT, West BL, Jameson JL (1998) A novel natural mutation in the thyroid hormone receptor defines a dual functional domain that exchanges nuclear receptor corepressors and coactivators. Mol Endocrinol 12:1888-1902.

44. Wurtz JM, Bourguet W, Renaud JP et al. (1996) A canonical structure for the ligand-binding domain of nuclear receptors. Nat Struct Biol 3:87-94

45. Zhang J, Hu X, Lazar MA (1999) A novel role for helix 12 of retinoid $X$ receptor in regulating repression. Mol Cell Biol 19:6448-6457

46. Hu X, Lazar MA (1999) The CoRNR motif controls the recruitment of corepressors by nuclear hormone receptors. Nature 402:93-96

47. Nagy L, Kao HY, Chakravarti D et al. (1997) Nuclear receptor repression mediated by a complex containing SMRT, mSin3A, and histone deacetylase. Cell 89:373-380

48. Perissi V, Staszewski LM, McInerney EM et al. (1999) Molecular determinants of nuclear receptor-corepressor interaction. Genes Dev 13:3198-3208

49. Shao D, Lazar MA (1997) Peroxisome proliferator activated receptor gamma, CCAAT/enhancer-binding protein alpha, and cell cycle status regulate the commitment to adipocyte differentiation. J Biol Chem 272:2147321478

50. Gerhold DL, Liu F, Jiang G et al.(2002) Gene expression profile of adipocyte differentiation and its regulation by peroxisome proliferator-activated receptor-gamma agonists. Endocrinology 143:2106-2118

51. Lopez GN, Webb P, Shinsako JH, Baxter JD, Greene GL, Kushner PJ (1999) Titration by estrogen receptor activation function-2 of targets that are downstream from coactivators. Mol Endocrinol 13:897-909

52. Jimenez-Lara AM, Aranda A (2000) Interaction of vitamin $\mathrm{D}$ and retinoid receptors on regulation of gene expression. Horm Res 54:301-305

53. Brun RP, Spiegelman BM (1997) PPAR gamma and the molecular control of adipogenesis. J Endocrinol 155: 217-218

54. Fajas L, Schoonjans K, Gelman L et al. (1999) Regulation of peroxisome proliferator-activated receptor gamma expression by adipocyte differentiation and determination factor $1 /$ sterol regulatory element binding protein 1 : implications for adipocyte differentiation and metabolism. Mol Cell Biol 19:5495-5503

55. Stone RL, Bernlohr DA (1990) The molecular basis for inhibition of adipose conversion of murine 3T3-L1 cells by retinoic acid. Differentiation 45:119-127

56. Hu X, Li Y, Lazar MA (2001) Determinants of CoRNRdependent repression complex assembly on nuclear hormone receptors. Mol Cell Biol 21:1747-1758

57. Deeb SS, Fajas L, Nemoto M et al. (1998) A Pro12Ala substitution in PPARgamma2 associated with decreased recepror acitivity, lower body mass index and improved insulin sensitivity. Nat Genet 20:284-287

58. Kubota N, Terauchi Y, Miki H et al. (1999) PPARg mediates high-fat diet-induced adipocyte hypertrophy and insulin resistance. Molecular Cell 4:597-609

59. Miles P, Barak Y, He W, Evans RM, Olefsky JM (2000) Improved insulin-sensitivity in mice heterozygous for PPAR- $\gamma$ defiency. J Clin. Invest 105:287-292

60. Yamauchi T, Waki H, Kamon Jet al.(2001) Inhibition of RXR and PPARgamma ameliorates diet-induced obesity and type 2 diabetes. J Clin Invest 108:1001-1013 